\title{
Kinetics and Mechanism of Gold Dendrite Electroformation on C(0001). Activation Energy for Gold Adatom Surface Diffusion
}

\author{
H. Martín, P. Carro, A. Hernández Creus, and S. González \\ Departamento de Química Física, Universidad de La Laguna, La Laguna, Tenerife, Spain \\ R. C. Salvarezza and A. J. Arvia* \\ Instituto de Investigaciones Fisicoquímicas Teóricas y Aplicadas (INIFTA), Sucursal 4, Casilla de Correo 16, \\ (1900) La Plata, Argentina
}

Received: June 19, 1998; In Final Form: February 10, 1999

\begin{abstract}
$\mathrm{Au}$ electrodeposition on $\mathrm{C}(0001)$ from aqueous solutions with different concentrations of $\mathrm{AuCl}_{3} \cdot \mathrm{HCl}$, at a constant ionic mass transport rate $\left(j_{\mathrm{L}}\right)$, in the temperature range $275 \leq T \leq 313 \mathrm{~K}$, results in the initial formation of nanometer-sized $\mathrm{Au}$ islands consisting of a central core and symmetrically distributed branches with the island fractal dimension $D_{\mathrm{f}}=1.6$. For all values of $T$, the time dependence of the Au island radius fulfills a $r \propto t^{n}$ relationship with $n=0.25 \pm 0.05$. At constant $T$, the density of Au islands $\left(N_{\mathrm{s}}\right)$ increases according to $N_{\mathrm{s}} \propto j_{\mathrm{L}}{ }^{X}$ with $X=0.69 \pm 0.03$. At constant $j_{\mathrm{L}}$, the value of $N_{\mathrm{s}}$ decreases as $T$ is increased, following an Arrhenius-type relationship. Kinetic data are consistent with a growth mechanism involving surface diffusion of $\mathrm{Au}$ adatoms from the island core towards branch tips. From the dependence of $N_{\mathrm{s}}$ on $T$ at constant $j_{\mathrm{L}}$, the activation energy for Au adatom surface diffusion results in $E_{\mathrm{a}}{ }^{*} \approx 11 \mathrm{Kcal} / \mathrm{mol}$. This figure is slightly smaller than $E_{\mathrm{a}}{ }^{*} \approx 14 \mathrm{Kcal} / \mathrm{mol}$ that has been reported for Au atom surface diffusion in $\mathrm{Cl}^{-}$-ion free acid solutions.
\end{abstract}

\section{Introduction}

The epitaxial growth of a solid phase on well-defined crystalline foreign substrate occurring far from equilibrium is a complex process in which different steps can be distinguished, namely, the initial formation of nuclei, nucleus growth forming two-dimensional (2D) or three-dimensional (3D) crystals, and finally, the overlapping of these crystals covering the substrate. ${ }^{1}$ The first and second steps lead to a surface consisting of patches of the substrate and islands of the new solid phase. Under certain experimental conditions, islands can be described as strongly disordered fractal patterns. ${ }^{2}$ The characteristics of these patterns are determined by the kinetics and mechanism of the growth process as can be concluded by comparing them to those resulting from different growth models.

The initial stages of island growth have been described by different growth models, in particular, the deposition, diffusion, and aggregation (DDA) model. ${ }^{1}$ For the DDA model, particles deposited on the substrate are incorporated into island edges, and those deposited on islands diffuse downward to be incorporated into island edges. Patterns resulting from this model consist of $2 \mathrm{D}$ islands, their shape resembling closely that expected from either diffusion-limited aggregation (DLA), ${ }^{3}$ or dendrite-like, ${ }^{4}$ or dense radial aggregation models, ${ }^{1}$ depending on subtle differences in the surface diffusion characteristics of arriving particles. The DDA model, although developed as a homoepitaxial model, generates growth patterns closely comparable to those resulting from heteroepitaxial experimental systems. This is the case, for instance, of DLA-like quasi-2D $\mathrm{Au}$ islands produced from vapor deposition on $\mathrm{Ru}(0001)$ at 298 $\mathrm{K},{ }^{2}$ although $\mathrm{Ag}$ and $\mathrm{Pt}$ dendritic islands are formed on $\mathrm{Pt}(111)$

\footnotetext{
* To whom all correspondence should be addressed.
}

from vapor deposition at $130 \mathrm{~K}^{4}$ and $200 \mathrm{~K},{ }^{5}$ respectively. The stability of dendrite tips has been attributed to the anisotropic corner diffusion of depositing adatoms. ${ }^{4,5}$ Furthermore, for $\mathrm{Cu}$ vapor-deposited on $\mathrm{Ni}(100)$ in the range $250-370 \mathrm{~K}$, the transition from compact to branched growth has been attributed to strain relief. ${ }^{6}$

Transmission electron microscopy and diffraction data ${ }^{7,8}$ on vapor-deposited $\mathrm{Au}$ on $\mathrm{C}(0001)$ grown far from equilibrium have shown initially a pseudomorphic growth that has been followed by the development of epitaxially grown branched islands. In this case, it has been observed that the increase in substrate temperature tends to change the growth mode from branching into compact islands. This change in morphology has been related to the enhancement of edge adatom diffusion. ${ }^{1,4}$ The equilibrium shape of Au crystals on $\mathrm{C}(0001)$ has only been observed after annealing for $70 \mathrm{~h}$ at $1273 \mathrm{~K},{ }^{9}$ turning the use of classical thermodynamic growth models ${ }^{10}$ for this system inapplicable. Recently, it has been found that, under certain experimental conditions, Au electrodeposition on $\mathrm{C}(0001)$ from acid aqueous electrolyte solutions at $298 \mathrm{~K}^{11}$ initially produces three-dimensional (3D) $\mathrm{Au}(111)$ islands followed by quasi-2D dendritic branching. In our knowledge this was the first evidence of quasi-2D nanometer-sized dendritic island formation by electrochemical deposition. In this case, the electrodeposition process is under mass transport control and it occurs in a potential $(E)$ window that is located negatively with respect to the potential of zero charge $\left(E_{\mathrm{pzc}}\right)$ of $\mathrm{Au}(111)$ in the solution. The origin of the dendritic growth mode has been related to the existence of step edge energy barriers and anisotropic corner diffusion of Au adatoms. ${ }^{4,5}$

This work focuses on the kinetics and mechanism of $\mathrm{Au}$ dendritic growth on $\mathrm{C}(0001)$ by electrodeposition, in the range 
$275 \leq T \leq 313 \mathrm{~K}$. Kinetic data allow us to conclude that $\mathrm{Au}$ surface atom diffusion plays a key role as rate-determining step in $\mathrm{Au}$ dendritic growth. The activation energy for Au adatom surface diffusion $\left(E_{\mathrm{a}}{ }^{*}\right)$ on $\mathrm{Au}$ resulting from the flux and temperature dependences of Au island density is $E_{\mathrm{a}}{ }^{*} \approx 11 \mathrm{Kcal} /$ mol. The existence of anisotropic energy barriers at step edges and anisotropic corner diffusion can explain the change in the $\mathrm{Au}$ island shape from quasi-2D compact to dendritic.

\section{Experimental Section}

The electrodeposition of Au was made in the range $275 \leq T$ $\leq 313 \mathrm{~K}$ on a freshly exfoliated $\mathrm{C}(0001)$ working electrode $\left(0.5 \mathrm{~cm}^{2}\right)$ using a conventional glass-made electrochemical cell provided with a $\mathrm{Pt}$ polycrystalline counter electrode, and a saturated calomel electrode (SCE) as reference. The value of the reference electrode potential at each $T$ was calculated using the following equation: ${ }^{12}$

$$
\begin{aligned}
E=0.2412-6.61 \times 10^{-4}(T-298)- \\
1.75 \times 10^{-6}(T-298)^{2}
\end{aligned}
$$

Potentials in the text are referred to the SCE scale at $T=298$ K.

The composition of aqueous working solutions was $c \mathrm{AuCl}_{3}$. $\mathrm{HCl}+0.5 \mathrm{M} \mathrm{NaClO}_{4}+1 \times 10^{-2} \mathrm{M} \mathrm{HClO}_{4}+0.92 \times 10^{-2} \mathrm{M}$ $\mathrm{NaCl}$, with $c$ varied in the range $5 \times 10^{-5} \mathrm{M} \leq c \leq 5 \times 10^{-4}$ $\mathrm{M}$. These solutions were prepared from analytical reagent-grade chemicals and MilliQ*-Millipore water, and deaerated by bubbling purified Ar prior to Au electrodeposition. The formation of $\mathrm{Au}$ islands was investigated by combining electrochemical techniques and ex situ scanning tunneling microscopy (STM).

Cathodic polarization curves covering the range $0.9 \geq E \geq$ $-0.1 \mathrm{~V}$ were made with a PAR instrument consisting of EQ\&G $173,175,178$, and 179 units, at the potential scan rate $v=1 \times$ $10^{-3} \mathrm{~V} / \mathrm{s}$ to approach free convection electrodeposition under quasi-steady-state conditions. These curves provided information about the kinetics of $\mathrm{Au}$ electrodeposition on $\mathrm{C}(0001)$, and allowed us to select the most convenient potential range to produce Au dendritic islands. In the range of $c$ and $T$ used in this work, runs were made at constant current density in the range $40 \leq j_{\mathrm{L}} \leq 140 \mu \mathrm{A} / \mathrm{cm}^{2}$, and electrodeposition charge density $(q)$ in the range $0.6 \leq q \leq 25 \mathrm{mC} / \mathrm{cm}^{2}$. Both $j_{\mathrm{L}}$ and $q$ are referred to the initial substrate surface area.

For ex situ STM imaging, the working electrode was removed from the electrochemical cell, rinsed by successive immersions in water, and finally, dried under Ar at room temperature. Immediately afterwards STM images were obtained using Nanoscope II E STM (Digital Instruments, Santa Barbara, CA) with $\mathrm{Pt}-\mathrm{Ir}$ nanotips operating in air. This operation mode was feasible because of the stability of the electrode surface in air. Images were taken at $0.5 \mathrm{nA}$ tunneling current, $0.2 \mathrm{~V}$ bias voltage, and scan rates usually in the order of $0.5 \mathrm{~Hz}$ for images $10 \times 10 \mu \mathrm{m}^{2}$ in size. For these conditions, either damage to or removal from the substrate of Au crystals by the tip could be prevented.

$\mathrm{Au}$ electrodeposits remained unaltered after STM imaging, as was concluded for each electrode by the coincidence of the values of $q$ determined from $\mathrm{Au}$ anodic stripping voltammetry before and after STM imaging.

\section{Results}

3.1. Cathodic Polarization Curves. The current density $(j)$ vs potential $(E)$ plots for $\mathrm{Au}$ electrodeposition on $\mathrm{C}(0001)$, run

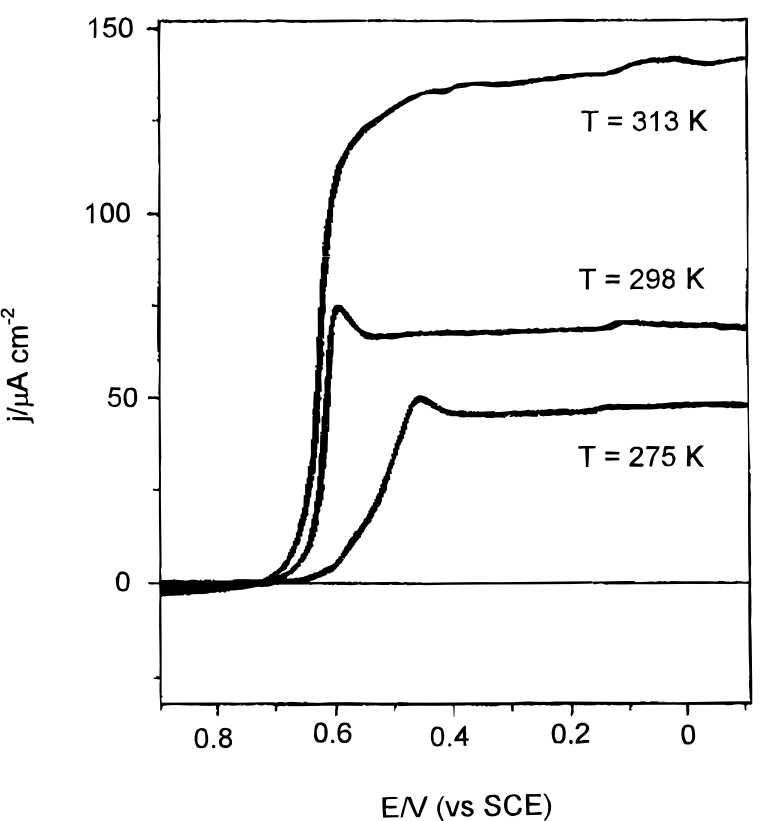

Figure 1. Current/potential curves for gold electrodeposition from aqueous $5 \times 10^{-4} \mathrm{M} \mathrm{AuCl}_{3} \cdot \mathrm{HCl}+0.5 \mathrm{M} \mathrm{NaClO}_{4}+0.01 \mathrm{M} \mathrm{HClO}_{4}$ on $\mathrm{C}(0001)$ made at $0.001 \mathrm{~V} / \mathrm{s}$ and different temperatures. A clear cathodic current plateau for $E<0.4 \mathrm{~V}$ can be observed.

at $v=0.001 \mathrm{~V} / \mathrm{s}$ starting from $E=0.9 \mathrm{~V}$ in the negative direction (Figure 1), exhibit a net cathodic current for $E<0.72$ $\mathrm{V}$ in the range $275 \leq T \leq 313 \mathrm{~K}$. The initial cathodic current is related to the nucleation of $\mathrm{Au}$ on defective sites of $\mathrm{C}(0001)$ according to the following reaction: ${ }^{11}$

$$
\begin{aligned}
& \mathrm{C}(0001)+m \mathrm{AuCl}_{4}^{-}+3 m \mathrm{e}^{-}= \\
& \mathrm{C}(0001)\{\mathrm{Au}\}_{m}+4 m \mathrm{Cl}^{-}
\end{aligned}
$$

where $\{\mathrm{Au}\}_{m}$ stands for a Au nucleus consisting of $m$ atoms on the $\mathrm{C}(0001)$ surface. Later, nuclei further grow by incorporating $\mathrm{Au}$ atoms discharged either on the substrate or directly on the $\mathrm{Au}$ island surface according to

$$
\begin{aligned}
& \mathrm{C}(0001)\{\mathrm{Au}\}_{m}+\mathrm{AuCl}_{4}{ }^{-}+ 3 \mathrm{e}^{-}= \\
& \mathrm{C}(0001)\{\mathrm{Au}\}_{m+1}+4 \mathrm{Cl}^{-}
\end{aligned}
$$

The standard potential of reaction $2 \mathrm{~b}$ in the working solution is $E^{\circ}=0.757 \mathrm{~V}$, and its isothermal temperature coefficient, $\mathrm{d} E^{\circ} /$ $\mathrm{d} T=-0.63 \times 10^{-3} \mathrm{~V} / \mathrm{K} .{ }^{13}$ In all cases, the cathodic current attains a limiting value $\left(j_{\mathrm{L}}\right)$ covering a relatively wide potential range.

For $T<313 \mathrm{~K}$, the cathodic limiting current is preceded by a current hump typical of a mass-transport-controlled electrochemical reaction. The initial slope of the $j$ vs $E$ curve increases and the potential of the current hump shifts positively as $T$ is increased.

The dependence of $j_{\mathrm{L}}$ on the $\mathrm{AuCl}_{4}{ }^{-}$concentration $c$ fits the equation for a mass-transport-controlled electrochemical process, ${ }^{14}$

$$
j_{\mathrm{L}}=\mathrm{z} F D_{\mathrm{i}} c /\langle\delta\rangle
$$

$\mathrm{z}=3$ being the number of electrons per reactant ion in either reaction $2 \mathrm{a}$ or $2 \mathrm{~b}, F$ the Faraday constant, $\langle\delta\rangle$ the average stationary diffusion layer thickness under free convection, and $D_{\mathrm{i}}$ the diffusion coefficient of the reactant species $\left(\mathrm{AuCl}_{4}{ }^{-}\right)$in 

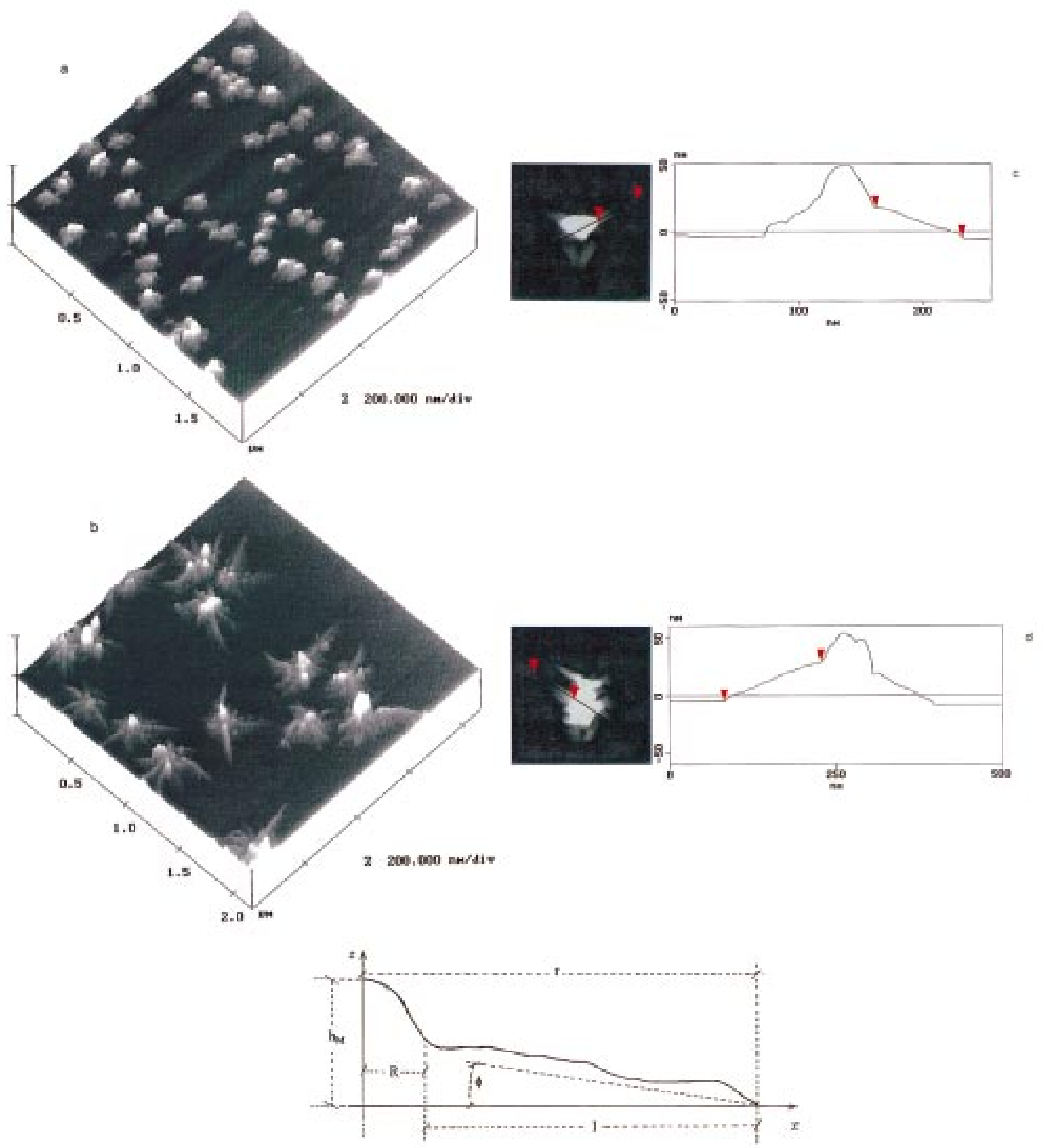

Figure 2. (a) and (b): Ex situ STM images $\left(2 \times 2 \mu \mathrm{m}^{2}\right.$, topographic mode) of gold islands on $\mathrm{C}(0001)$ produced from aqueous $5 \times 10^{-4} \mathrm{M}$ $\mathrm{AuCl}_{3} \cdot \mathrm{HCl}+0.5 \mathrm{M} \mathrm{NaClO}_{4}+0.01 \mathrm{M} \mathrm{HClO}_{4}$ under constant flux, $q=6 \mathrm{mC} / \mathrm{cm}^{2}, T=275 \mathrm{~K}$, and $T=298 \mathrm{~K}$, respectively. (c) and (d): Longitudinal cross sections from STM images for dendrites produced at $T=275$ and $298 \mathrm{~K}$, respectively. (e, bottom) A scheme (cross section) of the core (one-half) and dendrite branch of an island including geometric parameters used in the text.

the solution. According to eq 3 , the value of $j_{\mathrm{L}}$ could be adequately adjusted by changing $c$.

The temperature dependence of $j_{\mathrm{L}}$ fits an Arrhenius plot, i.e., the $\ln j_{\mathrm{L}}$ vs $1 / T$ plot results in a straight line. From the slope of this line, the experimental activation energy for the overall electrochemical process results in $E^{*}=3.8 \pm 0.2 \mathrm{Kcal} / \mathrm{mol}$. This figure is equal to $E_{\mathrm{D}} *$, the activation energy for the reactant diffusion in the solution. ${ }^{14}$
3.2. STM Imaging. Ex situ STM images of electrode surface domains resulting from $c=5 \times 10^{-4} \mathrm{M}$ and $q=6 \mathrm{mC} / \mathrm{cm}^{2}$ at $275 \mathrm{~K}\left(j_{\mathrm{L}}=0.04 \mathrm{~mA} / \mathrm{cm}^{2}\right)($ Figure $2 \mathrm{a})$ and $T=298 \mathrm{~K}\left(j_{\mathrm{L}}=\right.$ $0.06 \mathrm{~mA} / \mathrm{cm}^{2}$ ) (Figure $2 \mathrm{~b}$ ) show fractional coverage of the $\mathrm{C}(0001)$ substrate by randomly distributed $\mathrm{Au}$ islands of a rather uniform size and shape. Each island consists of a large number of tiny Au crystals with a high rounded central core and branches without tip splitting as expected for dendrites, emerging at $120^{\circ}$ 
a

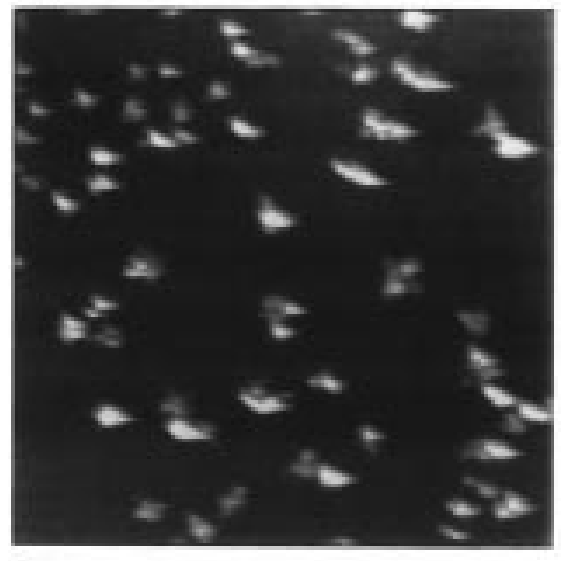

b
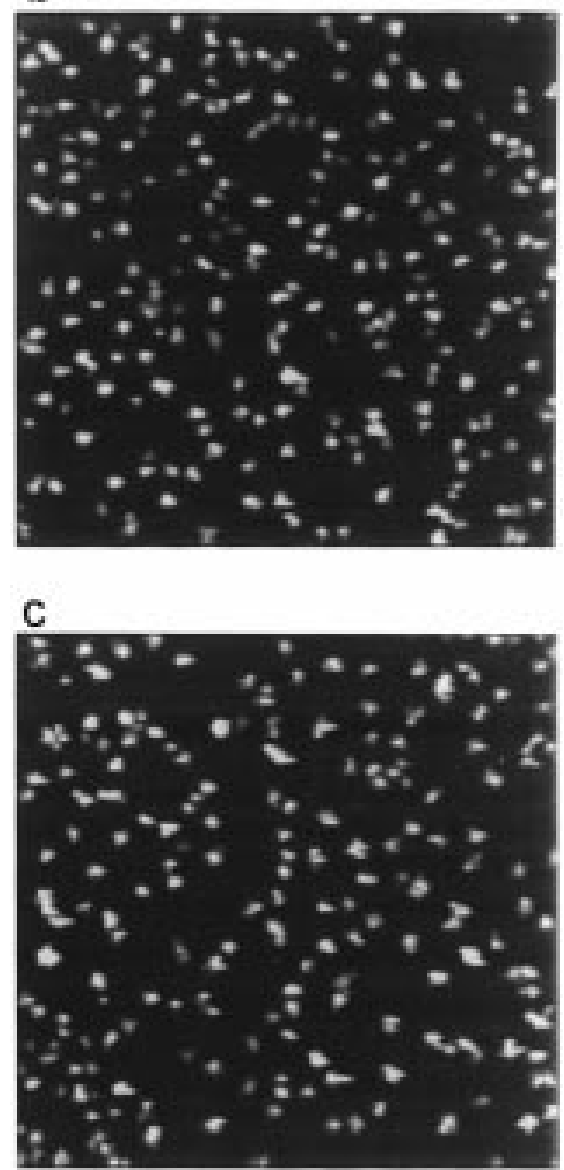
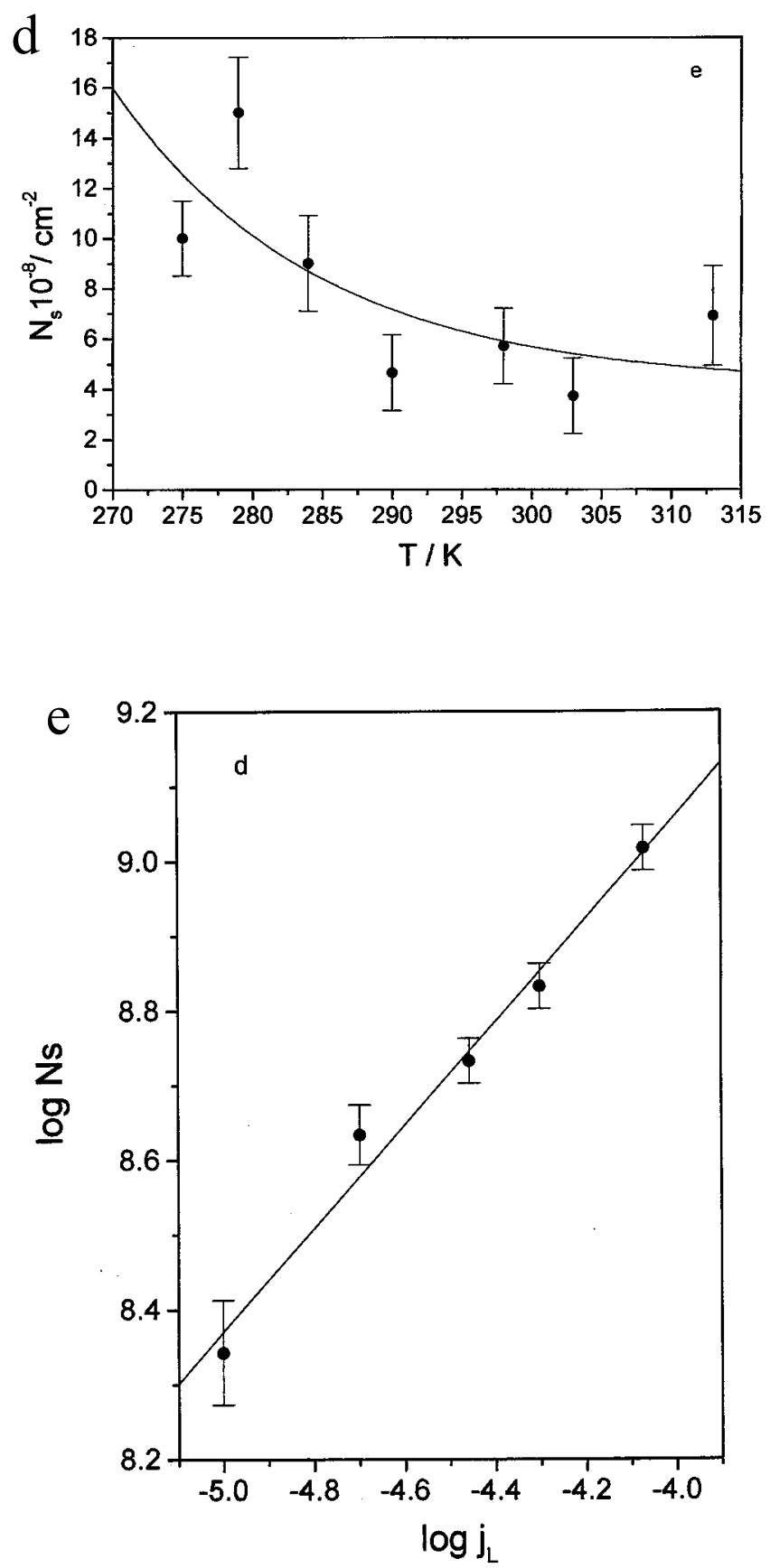

Figure 3. $(\mathrm{a}-\mathrm{c})$ : Ex situ STM images $\left(5 \times 5 \mu \mathrm{m}^{2}\right.$, topographic mode) of gold aggregates on $\mathrm{C}(0001)$ for $q=6 \mathrm{mC} / \mathrm{cm}^{2}$, at different values of $c$ and $T$. (a) $c=5 \times 10^{-5} \mathrm{M}, T=298 \mathrm{~K}$. (b) $c=5 \times 10^{-4} \mathrm{M}, T=275 \mathrm{~K}$, (c) $c=5 \times 10^{-4} \mathrm{M}, T=298 \mathrm{~K}$. (d) Log $N_{\mathrm{s}}$ vs $\log j_{\mathrm{L}}$ plot for $q=$ $6 \mathrm{mC} / \mathrm{cm}^{2}$. The slope of the straight line is $0.69 \pm 0.03$. (e) $N_{\mathrm{s}}$ vs $T$ plot from runs involving $q=6 \mathrm{mC} / \mathrm{cm}^{2}$.

angles. These patterns are consistent with the formation of Au(111) islands as reported elsewhere. ${ }^{11}$ The longitudinal cross section of a single branch (Figure $2 \mathrm{c}, \mathrm{d}$ ) reveals a sequence of terraces decreasing in height from the core border toward the branch tip by one or two-atom high steps.

A cross section of a typical $\mathrm{Au}$ island along the direction of one branch (Figure 2e) can be described in terms of the length of the largest branch $(l)$, the branch width $(w)$, the branch slope $(\phi)$, and the maximum island height at the core $\left(h_{\mathrm{M}}\right)$ (Figure $2 \mathrm{e})$. The value of $l$ is measured from the radius of the core $(R)$, and $\phi$ is defined as the average angle formed by the substrate plane and the branch surface plane measured from the tip. At constant $E$ and $q$, all these parameters depend on $T$. Thus, for $c=5 \times 10^{-4} \mathrm{M}$ and $q=6 \mathrm{mC} / \mathrm{cm}^{2}$, as $T$ is increased from 275 to $313 \mathrm{~K},(\langle l\rangle)$, the average value of $l$ increases, in contrast to $\langle\phi\rangle$, the average value of $\phi$ (Figure $2 \mathrm{c}, \mathrm{d}$ ). The small values of $\langle\phi\rangle$, and the fact that $\langle l\rangle\rangle\left\langle h_{\mathrm{M}}\right\rangle$ indicate that for dendrite growth $\mathrm{d}\langle l\rangle / \mathrm{d} t>\mathrm{d}\left\langle h_{\mathrm{M}}\right\rangle / \mathrm{d} t$. Otherwise, for a given $q$, the ratio $\langle l\rangle \mid\langle w\rangle$ becomes almost constant, irrespective of $T$.

Branched islands have also been observed for vapor-deposited $\mathrm{Au}$ on $\mathrm{C}(0001){ }^{7,8}$ However, in this case, the island surface is essentially smooth with $\langle\phi\rangle \approx 0 .{ }^{15}$ The difference between the island surface of these deposits and that of electrodeposited $\mathrm{Au}$ islands on $\mathrm{C}(0001)$ can be explained by a different growth 

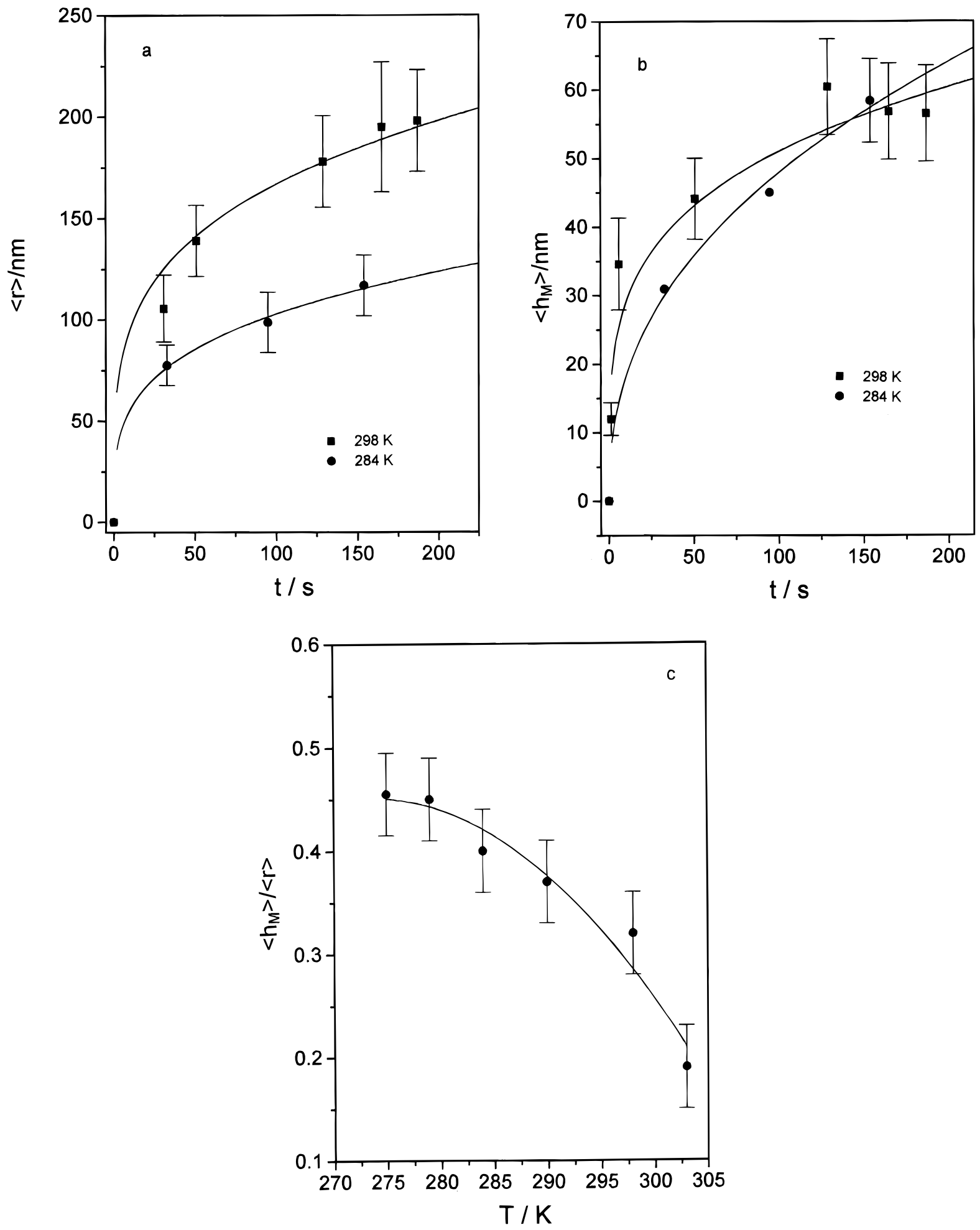

Figure 4. (a) Plots of $\langle r\rangle$ vs $\mathrm{t}$ for $T=284 \mathrm{~K}$ and $T=298 \mathrm{~K}$. (b) Plots of $\langle h\rangle$ vs $t$ obtained from gold dendritic branches produced at $T=284 \mathrm{~K}$ and $T=298 \mathrm{~K}$. (c) Plot of $\langle h\rangle\left\langle\langle r\rangle\right.$ vs $T$ resulting from runs involving $q=6 \mathrm{mC} / \mathrm{cm}^{2}$.

kinetics. Thus, the kinetics of vapor-deposited $\mathrm{Au}$ islands on $\mathrm{C}(0001)$ is determined by a surface reaction, whereas the electrodeposition of $\mathrm{Au}$ islands on the same substrate is governed by ionic mass transport from the solution side. In this case, growth normal to the substrate is enhanced at protrusions (island cores) leading to a nonzero slope between the central core and the branch tip. ${ }^{1}$

3.3. Density of $\mathbf{A u}$ Islands. The density of $\mathrm{Au}$ crystals $\left(N_{\mathrm{s}}\right)$ on $\mathrm{C}(0001)$ depends on both $j_{\mathrm{L}}$ and $T$ (Figure $\left.3 \mathrm{a}-\mathrm{c}\right)$. Thus, at $T=298 \mathrm{~K}, N_{\mathrm{s}}$ increases with $j_{\mathrm{L}}$ according to $N_{\mathrm{s}} \propto j_{\mathrm{L}}{ }^{X}$ with $X$
$=0.69 \pm 0.03$ (Figure 3d). On the other hand, for $c=5 \times$ $10^{-4} \mathrm{M}$ and $q=6 \mathrm{mC} / \mathrm{cm}^{2}, N_{\mathrm{s}}$ decreases exponentially with $T$ (Figure 3e).

3.4. Size Evolution of Au Islands. Results from experiments run at different $T$ and $c=5 \times 10^{-4} \mathrm{M}$ show that the average maximum radius $(\langle r\rangle)$ enclosing each Au crystal obeys the kinetic law $\langle r\rangle \propto t^{n}$ with $n=0.25 \pm 0.05$ (Figure 4a). This relationship is consistent with a growth process in which the surface diffusion of attaching particles plays a dominant role in the growth process. ${ }^{16}$ 
On the other hand, the average maximum value of island heights obeys a $\left\langle h_{\mathrm{M}}\right\rangle \propto t^{p}$ relationship with a $T$-dependent value of $p$ (Figure $4 \mathrm{~b}$ ), as $p$ changes from $0.25 \pm 0.05$, for $T=303$ $\mathrm{K}$, to $0.50 \pm 0.05$ for $T=275 \mathrm{~K}$ (Figure $4 \mathrm{~b}$ ). The increase in $p$ on decreasing $T$ suggests a decrease in the diffusion length of those $\mathrm{Au}$ atoms directly discharged on the Au island surface. Accordingly, the $\langle r\rangle /\left\langle h_{\mathrm{M}}\right\rangle$ ratio decreases as $T$ is decreased from 313 to $275 \mathrm{~K}$, assisting the formation of a rough pattern (Figure 4c).

3.5. Geometry of Au Islands. For all values of $T$ and $q<$ $0.6 \mathrm{mC} / \mathrm{cm}^{2}, \mathrm{Au}$ islands can be described as compact quasispherical objects obeying a euclidean geometry. Conversely, for $q>0.6 \mathrm{mC} / \mathrm{cm}^{2}$, branched islands with a fractal geometry are formed. These islands can be analyzed as $2 \mathrm{D}$ objects to evaluate their fractal dimension using the perimeter-area $(P-$ $A)$ method. ${ }^{16}$ For this purpose, cross sections of each Au island parallel to the substrate plane at a given height $\left(h_{\mathrm{c}}\right)$ measured from the substrate surface are obtained from STM images. After repeating this procedure for a number of $h_{\mathrm{c}}$ values, a collection of 2D Au islands is obtained. The $P$ vs $A$ relationship fulfills the following proportionality: ${ }^{17}$

$$
\log P \propto\left(D_{\mathrm{f}} / 2\right) \log A
$$

where $D_{\mathrm{f}}$ is the dimension of the object. From the $P-A$ method, when $h_{\mathrm{c}} \rightarrow 0$, all branches are included in the $2 \mathrm{D}$ island resulting in $D_{\mathrm{f}}=1.6 \pm 0.1$. Conversely, when $h_{\mathrm{c}} \rightarrow h_{\mathrm{M}}$, only the compact core of the island is analyzed and $D_{\mathrm{f}} \rightarrow 1$, i.e., islands approach a euclidean behavior.

\section{Discussion}

4.1. Possible Contributions to the Electrochemical Growth of Au Islands on C(0001). The initial electrochemical growth of $\mathrm{Au}$ islands on $\mathrm{C}(0001)$ involves the transport of reactants from the solution to the $\mathrm{C}(0001)$ surface, their discharge at $\mathrm{C}(0001)$ defective $\operatorname{sites}^{11}$ to form nuclei (reaction $2 \mathrm{a}$ ), and nucleus growth producing randomly distributed islands (reaction $2 \mathrm{~b})$. In this growth process two stages, one for $q<0.6 \mathrm{mC} /$ $\mathrm{cm}^{2}$ and the other one for $q>0.6 \mathrm{mC} / \mathrm{cm}^{2}$, can be distinguished. The first stage leads to compact Au islands, whereas the second results in branched $\mathrm{Au}(111)$ islands with $D_{\mathrm{f}}=1.6$.

Assuming that the discharge of $\mathrm{Au}$ ions on $\mathrm{C}(0001)$ is less efficient than that on $\mathrm{Au},{ }^{11}$ branching will occur mainly by $\mathrm{Au}$ adatoms spilling over from the core region of each island to dendrite tips. This process should involve the diffusion of $\mathrm{Au}$ adatoms on smooth $\mathrm{Au}(111)$ terraces and from terrace to terrace across monoatomic steps (Figure 5a). It should be remembered that surface diffusion of adatoms on single crystal (111) faces is asymmetric leading to dendrite formation, owing to the existence of two different types of steps. ${ }^{4-6}$ The terrace-toterrace atom diffusion assists further branch growth and secondary branching. ${ }^{11}$

According to the above description, surface diffusion of $\mathrm{Au}$ adatoms on $\mathrm{Au}$ in the absence of energy barriers at step edges would produce perfect $2 \mathrm{D}$ smooth islands growing in the direction parallel to the $\mathrm{C}(0001)$ plane, whereas the existence of asymmetric energy barriers for terrace-to-terrace surface atom diffusion would produce dendrites and control the rate of island growth in the vertical direction. In this case, the values of $D_{\mathrm{f}}$ and $\langle l\rangle /\langle w\rangle$ ratio, and the $\langle r\rangle \propto t^{1 / 4}$ relationship, are $T$ independent, providing a sound indication that the mechanism of $\mathrm{Au}$ island branching on $\mathrm{C}(0001)$ remains the same over the range of $T$ covered in this work.

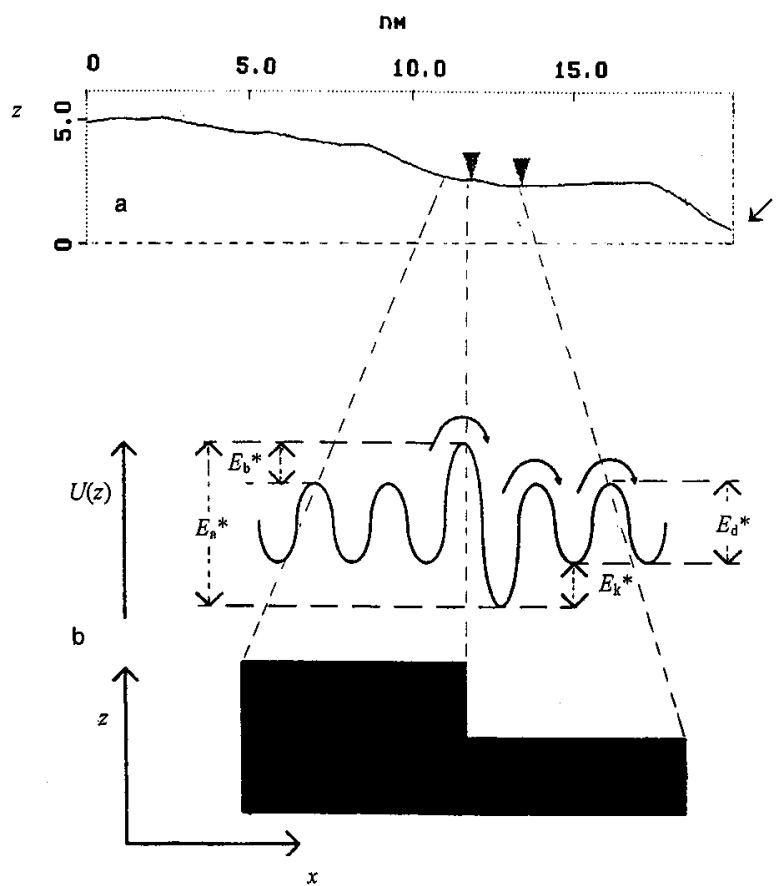

Figure 5. (a) Typical STM longitudinal profile of a gold dendritic branch electrodeposited on $\mathrm{C}(0001)$ from aqueous $5 \times 10^{-4} \mathrm{M} \mathrm{AuCl}_{3}$. $\mathrm{HCl}+0.5 \mathrm{M} \mathrm{NaClO}_{4}+0.01 \mathrm{M} \mathrm{HClO}_{4}$ under constant flux, $q=6$ $\mathrm{mC} / \mathrm{cm}^{2}$ and $T=298 \mathrm{~K}$. The arrow indicates the dendrite tip. (b) Scheme of a single atom high step resulting from a. The different activation energy barriers to surface diffusion of gold atoms are indicated.

4.2. Driving Force and Possible Energy Barriers for Au Adatom Surface Diffusion. The rate of displacement of $\mathrm{Au}$ adatoms from the core to branch tips is determined by different energy barriers to adatom surface diffusion (Figure 5b). These barriers impose a constraint to the terrace-to-terrace $\mathrm{Au}$ adatom surface diffusion. ${ }^{18}$

Considering the topography of $\mathrm{Au}$ islands, the accumulation of $\mathrm{Au}$ atoms at the cores, is favored by the smaller local value of $\delta$ at protrusions for the ionic mass-transport-controlled electrochemical reaction. ${ }^{11}$ Therefore, during Au electrodeposition the surface concentration of $\mathrm{Au}$ adatoms $\left(c_{\mathrm{ad}}\right)$ gradually changes from a maximum value at core regions to a practically null value at branch tips, so that the chemical potential gradient between the core region and branch becomes the driving force for surface diffusion. This fact implies that $\left(\Delta c_{\mathrm{ad}}\right)_{\mathrm{M}}$, the maximum concentration difference of $\mathrm{Au}$ adatoms, becomes constant as its average value at the core surface $\left(\left\langle\left(c_{\mathrm{ad}}\right)_{\mathrm{M}}\right\rangle\right)$ is proportional to the constant flux of electrodepositing particles $\left(j_{\mathrm{L}}\right)$, and $\left\langle c_{\mathrm{ad}}\right\rangle \Longrightarrow 0$ at the branch tip. In fact, considering that the branch surface consists of a series of terraces of length $l_{\mathrm{Ti}}$, decreasing in height from the central core towards the tip (Figure 2e), the overall driving force for $\mathrm{Au}$ adatom surface diffusion $\left(\Delta \mu_{\mathrm{ad}} / \Delta l\right)$ can be expressed as

$$
\sum_{i=1}^{n} \partial \mu_{\mathrm{ad}} / \partial l_{\mathrm{T}_{i}} \rightarrow\left(\Delta \mu_{\mathrm{ad}} / \Delta l\right)
$$

where $\mu_{\mathrm{ad}}$ and $l_{\mathrm{T}_{i}}$ denote the chemical potential of Au adatoms and the length of the $i$ th terrace $(i=1,2, \ldots, n)$, respectively. Taking into account that

$$
\left(\Delta \mu_{\mathrm{ad}} / \Delta l\right) \propto \Delta \ln c_{\mathrm{ad}} / \Delta l
$$




$$
\left(\Delta c_{\mathrm{ad}}\right)_{\mathrm{M}} / \Delta t \propto j_{\mathrm{L}}
$$

Then, it follows that,

$$
j_{\mathrm{L}} \propto v_{\mathrm{r}} \propto\left(\Delta c_{\mathrm{ad}}\right)_{\mathrm{M}} / \Delta l
$$

According to relationship $9 v_{\mathrm{r}}$, the growth rate of the tip front in the branch direction, is proportional to the $\mathrm{Au}$ adatom concentration gradient in the same direction.

4.3. Kinetics of Dendritic Branching. Let us consider the growth of 2D circular $\mathrm{Au}$ islands under constant flux involving terrace-to-terrace adatom surface diffusion. Taking into account that the island radius $(r)$, i.e. the characteristic length of the system, is given by the proportionality, ${ }^{1}$

$$
r^{4} \propto D_{\mathrm{s}} / j_{\mathrm{L}}
$$

$D_{\mathrm{s}}$ being the surface diffusion coefficient of $\mathrm{Au}$ atoms on $\mathrm{Au}$. The area $\left(A_{\mathrm{i}}\right)$ of the circular island fits the proportionality

$$
A_{\mathrm{i}} \propto r^{2} \propto\left(D_{\mathrm{s}} / j_{\mathrm{L}}\right)^{1 / 2}
$$

and for intermediate and high substrate coverage (Figure 3), the island density becomes

$$
N_{\mathrm{s}} \propto 1 / r^{2} \propto\left(D_{\mathrm{s}} / j_{\mathrm{L}}\right)^{-1 / 2}
$$

Expression 12 can be written as

$$
N_{\mathrm{s}} /\left(j_{\mathrm{L}}\right)^{1 / 2} \propto\left(D_{\mathrm{s}}\right)^{-1 / 2}
$$

Otherwise, the temperature dependence of $D_{\mathrm{s}}$ is given by ${ }^{16}$

$$
D_{\mathrm{s}} \propto \mathrm{e}^{-E_{\mathrm{a}} * / R T}
$$

Then, from eqs 13 and 14 the following proportionality holds

$$
N_{\mathrm{s}} /\left(j_{\mathrm{L}}\right)^{1 / 2} \propto \mathrm{e}^{E_{\mathrm{a}} * 2 R T}
$$

leading to a linear $\ln N /\left(j_{\mathrm{L}}\right)^{1 / 2}$ vs $T^{-1}$ plot with the slope $=E_{\mathrm{a}}{ }^{*} /$ 2.

The same analysis can be extended to dendritic islands $\left(D_{\mathrm{f}}\right.$ $=1.6$ ) resulting from terrace-to-terrace adatom surface diffusion towards branch tips involving the simultaneous shift of step edges and branch tips. In this case,

$$
N_{\mathrm{s}} /\left(j_{\mathrm{L}}\right)^{0.63} \propto \mathrm{e}^{0.63 E_{\mathrm{a}}{ }^{*} / R T}
$$

Then, at constant $T$, expression 16 predicts a linear $N_{\mathrm{s}}$ vs $\left(j_{\mathrm{L}}\right)^{0.63}$ dependence that is very close to that resulting from experimental data (Figure 6). Therefore, from the slope of the $\ln \left(N_{\mathrm{s}} / j_{\mathrm{L}}{ }^{X}\right)$ vs $1 / T$ plot (Figure 6) the value $E_{\mathrm{a}}{ }^{*} \approx 11 \mathrm{Kcal} \mathrm{mol}^{-1}$ is obtained. This figure is smaller than $E_{\mathrm{a}}{ }^{*} \approx 14 \mathrm{Kcal} \mathrm{mol}^{-1}$, which has been reported for $\mathrm{Au}$ atom surface diffusion in $\mathrm{Cl}^{-}$-ion-free acid solutions. ${ }^{19}$ This difference, however, can be understood since the presence of $\mathrm{Cl}^{-}$ions in the solution increases the surface mobility of $\mathrm{Au}$ adatoms. It is known that the adsorption of $\mathrm{Cl}^{-}$ ions decreases the $\mathrm{Au}-\mathrm{Au}$ bond energy. ${ }^{20,21}$

\section{Conclusions}

(i) The ex situ STM topography of Au islands electrodeposited on $\mathrm{C}(0001)$ at constant flux under ionic mass transport control, in the range $275<T<313 \mathrm{~K}$, exhibits only a compact quasi spherical core for $q<0.6 \mathrm{mC} / \mathrm{cm}^{2}$, and a core decorated with symmetrically distributed dendritic branching for $q>0.6$ $\mathrm{mC} / \mathrm{cm}^{2}$. Dendritic islands behave as fractals with the dimension

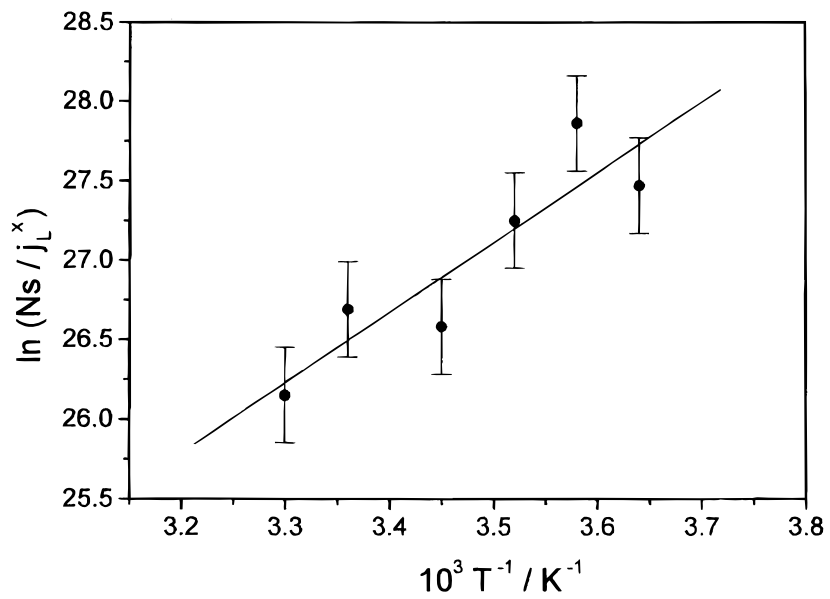

Figure 6. $\ln \left(N_{\mathrm{s}} / j_{\mathrm{L}}{ }^{X}\right)$ vs $T^{-1}$ plot. Data resulting from runs involving $q=6 \mathrm{mC} / \mathrm{cm}^{2}$. The slope of the straight line leads to $E_{\mathrm{a}}{ }^{*} \approx 11 \mathrm{Kcal} /$ mol.

$D_{\mathrm{f}}=1.6$. (ii) The rate of displacement of branch tips measured from STM imaging data can be explained by a Au adatom surface diffusion mechanism. (iii) The driving force for the directional $\mathrm{Au}$ adatom surface diffusion is the quasi-steady chemical potential gradient established longitudinally along each branch from the island core to branch tip. (iv) From the temperature and flux dependences of island density, the energy barrier to Au-adatom surface diffusion results in $E_{\mathrm{a}} * \approx 11 \mathrm{Kcal} /$ mol.

Acknowledgment. This work was financially supported by Project PB94-0592A (DGICYT), Spain, and PICT 97-1993 from Agencia Nacional de Promoción Científica y Tecnológica and Grant PIP 014/97 from Consejo Nacional de Investigaciones Científicas y Técnicas, Argentina.

\section{Glossary}

$A_{\mathrm{i}}$

$\mathrm{ad}$

$c$

$c_{\mathrm{ad}}$

$\left\langle c_{\mathrm{ad}}\right\rangle$

$\left(c_{\mathrm{ad}}\right)_{\mathrm{M}}$

$D_{\mathrm{f}}$

DDA

DLA

$D_{\mathrm{i}}$

$D_{\mathrm{s}}$

E

$E^{\mathrm{o}}$

$E_{\text {pzc }}$

$E^{*}$

$E_{\mathrm{D}}^{*}$

$E_{\mathrm{a}}{ }^{*}$

F

$\mathrm{F}$

HOPG

$h_{\mathrm{M}}$

$\left\langle h_{\mathrm{M}}\right\rangle$ area resulting from the "islands and lakes"procedure used to determine $D_{\mathrm{f}}$

area of circular island

adatom

molar concentration of discharging ions

molar concentration of adatoms

average molar concentration of adatoms

maximum molar concentration of adatoms

fractal dimension

deposition, diffusion and aggregation

diffusion limited aggregation

diffusion coefficient of ions in the solution

surface diffusion coefficient of adatoms

electrode potential

standard electrode potential

potential of zero charge

experimental activation energy for transport of ions in the solution derived from electrochemical data

activation energy for the diffusion of reactive species in the solution

activation energy for adatom surface diffusion

Faraday constant

flux of depositing particles

highly oriented pyrolitic graphite

maximum height at the island core

average maximum height at the island core 
$h_{\mathrm{c}} \quad$ height of planes parallel to the substrate plane used in the P-A method to evaluate the fractal dimension

apparent cathodic current density referred to the $\mathrm{C}(0001)$ surface area

$j_{\mathrm{L}} \quad$ apparent cathodic limiting current density

$k \quad$ Boltzmann constant

$l \quad$ length of the largest dendrite branch

$\langle l\rangle \quad$ average length of the largest dendrite branches

$l_{\mathrm{T} i} \quad$ length of the ith terrace

$m$

$N_{\mathrm{s}}$

$n$

$n$ number of atoms in a Au nucleus

island density

exponent in the $\langle r\rangle \propto t^{n}$ relationship

number of terraces forming a dendritic branch

perimeter resulting from the "islands and lakes"procedure used to determine $\mathrm{D}_{\mathrm{f}}$

exponent at the $\left\langle h_{\mathrm{M}}\right\rangle \propto t^{p}$ relationship

apparent charge density related to gold electrodeposition

island core radius

universal gas constant

maximum radius enclosing island

average maximum radius enclosing island

saturated calomel electrode

scanning tunneling microscopy

temperature

time

potential energy

electric potential scanning rate

displacement rate of the dendrite tip

width of a dendrite branch

exponent in the $N \approx j_{\mathrm{L}}{ }^{X}$ relationship

cartesian coordinate

cartesian coordinate

number of electrons per discharging ion

average Nernst diffusion layer thickness

angle formed by the substrate plane and the upper dendrite plane

average angle formed by the substrate plane and the upper dendrite plane $\mu_{\mathrm{ad}} \quad$ chemical potential of adatoms

2D two dimensional

3D three dimensional

\section{References and Notes}

(1) Barabasi, A. L.; Stanley, E. In Fractal Concepts in Surface Growth; Cambridge University Press: Cambridge, 1995

(2) Hwang, R. Q.; Schroder, J.; Gunther, G.; Behm, R. J. Phys. Rev. Lett. 1991, 67, 3279 .

(3) Meakin, P. In The Fractal Approach to the Heterogeneous Chemistry; Avnir, D., Ed.; Wiley: New York, 1989, p 131 and references therein.

(4) Brune, H.; Roder, H.; Bromann, K.; Kern, K.; Jacobsen, J.; Norskov, J. Surf. Sci. 1996, 349, L115.

(5) Hohage, M.; Bott, M.; Morgenstern, M.; Zhang, Z.; Michely, T.; Comsa, G. Phys. Rev. Lett. 1996, 76, 2366.

(6) Mueller, B., Nedelman, L., Fischer, B., Brune, H., Barth, J., Kern, K. Phys. Rev. Lett. 1998, 80, 2645.

(7) Darby, T. P., Wayman C. M. J.Cryst. Growth 1975, 28, 41. Wayman, C. M.; Darby, T. P. J. Cryst. Growth 1975, 28, 53.

(8) Nishitani, R.; Kasuya, A.; Kubota, S.; Nishina, Y. J. Vac. Sci. Technol. 1991, B9, 806

(9) Heyraud, J. C., Metois, J. J. J. Cryst. Growth 1980, 50, 571

(10) Budevski, E.; Staikov, G.; Lorenz, W. J., In Electrochemical Phase Formation and Growth; VCH: Weinheim, 1996.

(11) Martín, H.; Carro, P.; Hernández Creus, A.; González, S.; Salvarezza, R. C.; Arvia, A. J. Langmuir 1997, 13, 110.

(12) Hill, G. J.; Ives, J. G. In Reference Electrodes; Ives, D. G., Janz, G., Eds.; Academic Press: New York, 1961; Chapter 3, p. 127.

(13) Schmid, G. M.; Curley-Fiorino, M. E. In Encyclopedia of Electrochemistry of the Elements; Bard, A. J., Ed.; Marcel Dekker: New York, 1975; vol. IV, p 87

(14) Glasstone, S.; Laidler, K. J.; Eyring, H. In The Theory of Rate Processes; McGraw-Hill: New York and London, 1941; Chapter 9, p 480; Arvia, A. J.; Marchiano, S. L. In Los Fenómenos de Transporte en Electroquímica; Comisión de Investigaciones Científicas: Provincia de Buenos Aires, 1971; Chapter 12, p 251.

(15) Blum, B. B.; Salvarezza, R. C.; Arvia, A. J. In preparation.

(16) Pimpinelli, A; Villain, J.; Wolf, D. E.; Metois, J.; Heyraud, J. C.; Elkinani, I.; Uimin, G. Surf. Sci. 1993, 295, 143.

(17) Gómez-Rodríguez, J. M.; Baró, A. M.; Vázquez, L.; Salvarezza, R. C.; Vara, J. M.; Arvia, A. J. J. Phys. Chem. 1992, 96, 347.

(18) Li, Y.; DePristo A. E. Surf. Sci. 1996, 351, 189.

(19) Alonso, C.; Salvarezza, R. C.; Vara, J. M.; Arvia, A. J.; Vázquez, L.; Bartolomé, A.; Baró, A. M. J. Electrochem. Soc. 1990, 137, 2161.

(20) Trevor, D. J.; Chidsey, C. E. D.; Loiacono, D. N., Phys. Rev. Lett. 1989, 62, 929 .

(21) García, P.; Gómez, M.; Salvarezza, R. C.; Arvia, A. J. J. Electroanal. Chem. 1993, 347, 237. 